\title{
Development of Dentalium Following Removal of D-Quadrant Blastomeres at Successive Cleavage Stages
}

\author{
James Newton Cather ${ }^{1}$ and Nicolaas Hendrikus Verdonk ${ }^{2}$ \\ ${ }^{1}$ Division of Biological Science, The University of Michigan, Ann Arbor, Michigan 48109, USA \\ ${ }^{2}$ Zoological Laboratory, The University of Utrecht, Padualaan 8, Utrecht, The Netherlands
}

\begin{abstract}
Summary. Each primary micromere and macromere of the D-quadrant of Dentalium was deleted, through the mesentoblast stage, to investigate the way in which the polar lobe cytoplasm exerts its influence on development. $-D$ and $-1 D$ embryos form an apical tuft but no posttrochal structures. $-2 \mathrm{D}$ embryos form an apical tuft and a reduced posttrochal region without a shell. $-3 \mathrm{D}$ and $-4 \mathrm{D}$ are externally similar to control embryos. $-1 \mathrm{~d}$ embryos and $-1 \mathrm{c}$ embryos have an apical tuft with a reduced number of cilia. Embryos in which both $1 \mathrm{c}$ and $1 \mathrm{~d}$ are deleted lack the apical tuft. $-2 \mathrm{~d}$ embryos lack shell and most other posstrochal structures. $-3 \mathrm{~d}$ and $-4 \mathrm{~d}$ embryos appear externally equivalent to controls.

The polar lobe cytoplasm exerts its influence sequentially, and as in Ilyanassa the maximal effect is at the third quartet stage.
\end{abstract}

Key words: Mollusca - Embryology experimental - Development analysis - Dentalium - Invertebrate development.

\section{Introduction}

Wilson's (1904) study of the polar lobes influence on development has been of paramount importance in the conceptual growth of the field of embryology. It is remarkable that his experiments with Dentalium were neither confirmed nor extended for more than 60 years when Verdonk (1968a, b), Timmermans et al. (1970), Geilenkirchen et al. (1970) and Verdonk et al. (1971) undertook these investigations. Recently Van Dongen and Geilenkirchen $(1974,1975)$ and Van Dongen (1976a, b; 1977) have studied the cell lineage of both normal and lobeless embryos while Reverberi $(1970,1971,1972)$ has considered the fine structure and cytochemistry of oocytes and eggs of Dentalium.

Through the years it has become apparent that those embryos considered to be classic 'mosaic' embryos such as Dentalium, Ilyanassa, and Patella (see Clement 1971; Cather 1971; Van den Biggelaar 1977) have a complex array 
of cell and tissue interactions. Morrill et al. (1973) have shown essentially complete regulation after deletion of one blastomere at the 2-cell stage of Lymnaea. Verdonk and Cather (1973), Cather and Verdonk (1974), Dohmen and Verdonk $(1974,1979)$ and Cather et al. (1976) have shown that lobe dependent features require the presence of the vesicles of the vegetal body in Bithynia which presumedly are distributed to the $\mathrm{C}$ macromere as well as to D.

With these changes in viewpoint, we felt it to be necessary to investigate the way in which the polar lobe material of the D quadrant exerts its influence in Dentalium, as Clement (1962) did with Ilyanassa, by sequentially deleting the blastomeres of the D quadrant.

\section{Materials and Methods}

The work for this paper was done at the Station Biologique de Roscoff, on the north coast of Brittany, France, with the eggs and embryos probably of Dentalium vulgare da Costa. These specimens although more like $D$. vulgare have intergrading characters with $D$. entalis $\mathrm{L}$. Voucher specimens \# 243607 are in the collection of the Mollusk Division, Museum of Zoology, The University of Michigan. Animals dredged from depths just below the intertidal to $30 \mathrm{~m}$ were brought into the laboratory and kept in a $10 \mathrm{~cm}$ layer of sand in plastic dishpans. A gentle stream of fresh sea water flowed into the containers so that the sand was not disturbed. In this situation, animals remain in excellent condition for at least 6 weeks and probably for considerably longer. Animals were isolated in finger bowls of filtered sea water at room temperature when gametes were required. Although they were isolated at different periods throughout the day, most spawned between 11.00 and $14.00 \mathrm{~h}$. The Dentalium were therefore routinely isolated at 9.30.

After the animals spawned, the eggs were rinsed in Millipore filtered antibiotic sea water (ASW) containing $200 \mu \mathrm{g} / \mathrm{ml}$ of streptomycin sulfate and $100 \mathrm{units} / \mathrm{ml}$ penicillin $\mathrm{G}$, and fertilized with a drop of sperm suspension directly from a finger bowl containing a male. The percentage of eggs fertilized decreased rapidly after spawning and the percentage of polyspermic eggs and eggs with abnormal cleavages increased. The optimal period for fertilization is within the first half hour after spawning.

Operations were done with hand pulled glass needles. Cells to be deleted had to be cut clear across the surface and cleaned out from their position on the embryo. Simple penetration of the cell by a needle does not lead to cytolysis.

Embryos were reared in Boveri dishes in ASW. Only 3-4 operated embryos or about a dozen control embryos were kept in a single dish.

Each embryo was studied at several stages in the first day or two, to determine its general characteristics and the appearance and nature of its ciliation. Embryos were fixed when it appeared that development was not progressing but while the embryos were still motile and in good condition. Other embryos were observed until they died. Embryos were fixed in Da Fano's fixative, stained with $\mathrm{A}_{\mathrm{g}} \mathrm{NO}_{3}$ according to the method of Van Dongen and Geilenkirchen (1974), and prepared as whole mounts. Other embryos, fixed in Bouin's fixative were treated according to usual histological methods. Serial sections of 5-7 $\mu \mathrm{m}$ were stained with iron hematoxylin and eosin.

\section{Results}

\section{Control and Lobeless Embryos}

Normal development of Dentalium vulgare is in complete agreement with the description of Kowalevsky (1883) of the development of Dentalium dentale except 
Table 1. Summary of operations

\begin{tabular}{|c|c|c|c|c|}
\hline \multirow{2}{*}{$\begin{array}{l}\text { Cell(s) } \\
\text { deleted }\end{array}$} & \multirow{2}{*}{$\begin{array}{l}\text { Cells } \\
\text { remaining }\end{array}$} & \multirow{2}{*}{$\begin{array}{l}\text { Age (hs) } \\
\text { (Number } \\
\text { of embryos) }\end{array}$} & \multicolumn{2}{|c|}{ General results } \\
\hline & & & $\begin{array}{l}+ \text { Present } \\
\text { Apical tuft }\end{array}$ & $\begin{array}{l}\text { - Absent } \\
\text { Posttrochal region }\end{array}$ \\
\hline -1st polar lobe & - & $48(16)$ & - & - \\
\hline-2 nd polar lobe & - & $48(20)$ & + & - \\
\hline$-\mathrm{CD}$ & $A B$ & $48(27)$ & - & - \\
\hline$-A B$ & $\mathrm{CD}$ & $48(15) 96(6)$ & \multicolumn{2}{|c|}{ Displaced + Some structures } \\
\hline$-\mathrm{D}$ & $\mathrm{ABC}$ & $48(32) 72(9)$ & + & - \\
\hline$-1 \mathrm{D}$ & $A B C+1 d$ & $48(9) 72(39)$ & + & - \\
\hline$-2 \mathrm{D}$ & $\mathrm{ABC}+1 \mathrm{~d}+2 \mathrm{~d}$ & $48(20) 72(8)$ & + & Some structures \\
\hline$-3 \mathrm{D}$ & $A B C+1 d+2 d+3 d$ & $48(9) 72(9) 96(2)$ & + & Normal \\
\hline$-4 \mathrm{D}$ & $A B C+1 d+2 d+3 d+4 d$ & $48(2) 72(4) 96(3)$ & + & Normal \\
\hline$-1 d$ & $\mathrm{ABC}+1 \mathrm{D}$ & $48(16)$ & $\begin{array}{l}\text { Reduction } \\
\text { of cilia }\end{array}$ & Normal \\
\hline$-1 \mathrm{c}$ & $\mathrm{ABD}+\mathrm{lC}$ & $48(6)$ & $\begin{array}{l}\text { Reduction } \\
\text { of cilia }\end{array}$ & Normal \\
\hline$-1 \mathrm{eld}$ & $A B+1 C+1 D$ & $48(3)$ & - & Normal \\
\hline$-2 \mathrm{~d}$ & $A B C+2 D+1 d$ & $48(9) 72(25)$ & + & $\begin{array}{l}\text { Some structures, } \\
\text { no shell }\end{array}$ \\
\hline$-3 \mathrm{~d}$ & $A B C+3 D+1 d+2 d$ & $48(2) 72(8) 96(4)$ & + & $\begin{array}{l}\text { With foot, shell, } \\
\text { etc, variable }\end{array}$ \\
\hline$-4 \mathrm{~d}$ & $\mathrm{ABC}+4 \mathrm{D}+1 \mathrm{~d}+2 \mathrm{~d}+3 \mathrm{~d}$ & $48(2) 72(3) 96(3)$ & + & Normal \\
\hline
\end{tabular}

that the rate of development of the Mediterranean species is more rapid. The lower temperatures at Roscoff may account for the differences.

Although Van Dongen and Geilenkirchen (1975) and Van Dongen (1976a, b) had done extensive studies of lobeless embryos of Dentalium vulgare, we have repeated these experiments, as we needed reference-embryos for our experiments on development following removal of the D-quadrant at successive cleavage stages. The first (Fig. 6) and second polar lobes (Fig. 7) were removed and development was observed. Our results, which included 16-20 embryos in each case, were in agreement with those of Van Dongen and Geilenkirchen (1975) and Van Dongen (1976a, b). They confirmed the results of Wilson (1904), Verdonk et al. (1971), on Dentalium dentale and the results of Verdonk (1968a) on Dentalium antillarum. A summary of experiments with the ages of embryos at the time of fixation is presented in Table 1.

\section{One-Half Embryos}

$A B$ 1/2-Embryos. The $27 \mathrm{AB} 1 / 2$-embryos studied were very uniform in character (Fig. 4). They tended to be radially symmetrical during cleavage and gastrulation although the prototroch often had gaps and was irregular in its placement around the vegetal pole. No apical tuft, or posttrochal region formed; neither did any posttrochal structures appear at later periods. Partial exogastrulae occurred in about $1 / 4$ of the cases. All embryos developed short cilia on the 


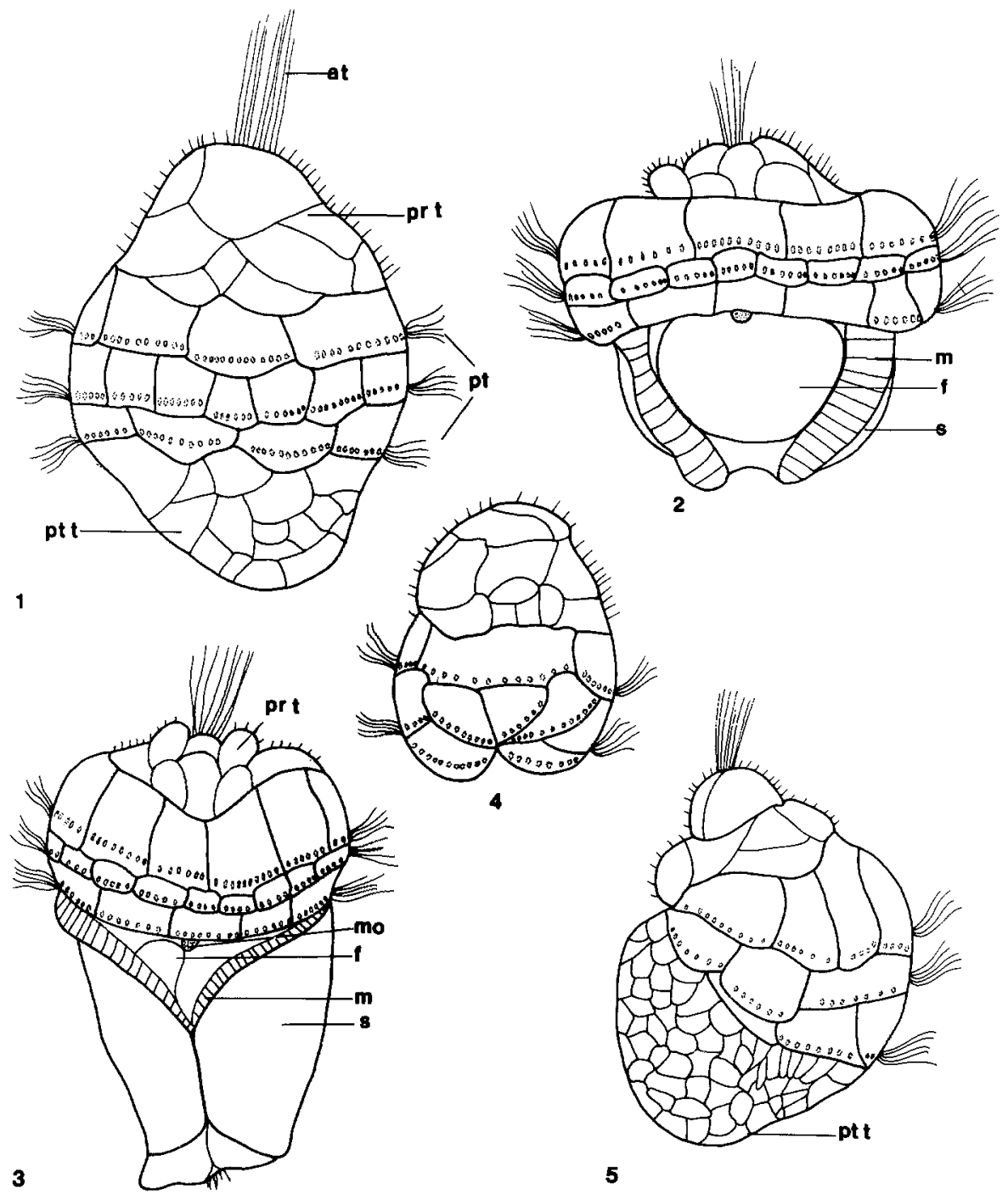

Fig. 1. Normal trochophore larva of Dentalium at about $28 \mathrm{~h}$ after fertilization. Apical tuft (at), pre-trochal region $(p r t)$, prototroch $(p t)$, posttrochal region $(p t t)$. The small circles in the prototrochal cells represent basal bodies. All drawings are camera lucida tracings of silver stained larvae $\times 230$

Fig. 2. Control larva about $72 \mathrm{~h}$ after fertilization, undergoing major organogenesis. Foot $(f)$, mantle $(m)$, shell $(s) . \times 230$

Fig. 3. Control larva 4 days old. Elongation and gradual metamorphosis leads to settling about 2 days later. Foot $(f)$, mantle $(m)$, mouth $(m o)$, pretrochal region $(p r t)$, shell $(s) . \times 230$

Fig. 4. AB $1 / 2$ larva $48 \mathrm{~h}$ after fertilization. Note the absence of the apical tuft and posttrochal region and the poor organization of the prototroch. $\times 230$

Fig. 5. CD $1 / 2$ larva $48 \mathrm{~h}$ after fertilization. The apical tuft is asymmetrically located. The prototroch is abnormal and the posttrochal region $(p t t)$ is unusually large. $\times 230$ 

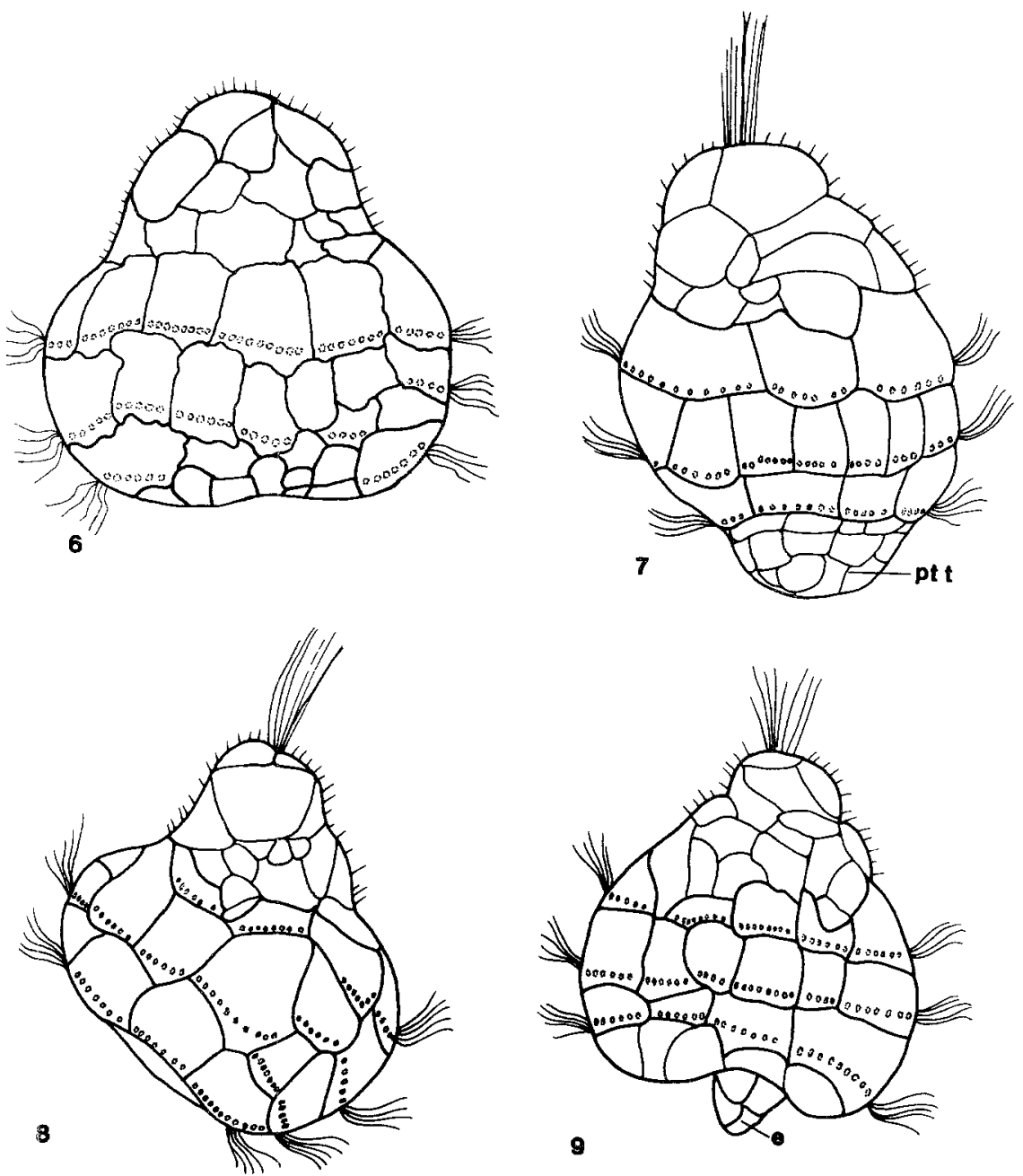

Fig. 6. Larva at $72 \mathrm{~h}$ after removal of the first polar lobe. The apical tuft and posttrochal region are missing. The lower prototroch is incomplete. $\times 230$

Fig. 7. Larva at $72 \mathrm{~h}$ after removal of the second polar lobe. The apical tuft is present, the prototroch is complete and there is a reduced posttrochal region $(p t t) . \times 230$

Fig. 8. Larva at $48 \mathrm{~h}$ after removal of the $\mathrm{D}$ macromere. The apical tuft is present, the prototroch is asymmetrical and the posttrochal region is essentially absent. $\times 230$

Fig. 9. Larva $72 \mathrm{~h}$ after removal of the $1 \mathrm{D}$ macromere. The apical tuft is present, the prototroch is uniform and there is a vegetal extrusion of endoderm $(e) . \times 230$

pretrochal cells. The one exogastrula sectioned failed to form a gut cavity while the 4 gastrulated embryos sectioned have a clearly defined enteron.

CD 1/2-Embryos. A total of 16 CD 1/2-embryos were prepared as whole mounts, and 5 were sectioned. Cleavage was partial; the time of cleavage was the same 
as in control embryos, and the polar lobe of the second cleavage was typical in all respects. CD 1/2-larvae were never radially symmetrical but showed definite defects due to the absence of the $A B$ quadrant blastomeres. The apical tuft is dislocated toward the side and the prototroch is incomplete on the same side (Fig. 5). The posttrochal region is relatively larger than in the control embryos but never forms normal posttrochal structures. No shell or shell gland was observed but extensions of the epithelium indicate an attempt at mantle formation. Statocysts were present in 3 of the 5 sectioned embryos, a gut cavity was usually present. No cerebral pits were observed in the pretrochal region. None of these embryos formed a recognizable foot but ciliated columnar epithelial patches typical of the foot were observed in the general region of the statocyst.

\section{Deletion of D-Quadrant Macromeres}

$A B C$-Embryos $(-D)$. Embryos developed in a consistent and uniform way with little variation after removal of the D-macromere. Whole mounts were prepared of 34 larvae and 7 were sectioned. Cleavage was partial and recognizably tripartite even in the trochophore. Four of the 41 embryos carefully studied lacked apical tufts, but these structures were well developed in the rest (Fig. 8). Gastrulation was usually complete, although small endodermal protrusions at the vegetal pole were observed in 3 cases. The prototroch usually consisted of 3 rows and gaps were seldom present. The posttrochal region was absent in the trochophore and no posttrochal structures ever formed. These embryos resemble those from which the second polar lobe was removed. Endodermal differentiation is similar to that of lobeless embryos where the enteron remains anterior in position and differentiates into typical liver tissue. No hindgut can be distinguished.

$A B C+1 d$-Embryos $(-1 D)$. These embryos which have all the cells of the 1 st quartet present have better prototroch development than $-\mathrm{D}$-larvae. The prototroch usually is of the typical evenly spaced three rows without gaps. Of the 37 embryos prepared as whole mounts and the 11 sectioned embryos, 12 were exogastrulae with the endodermal protrusions ranging from small (Fig. 9) to large. In living embryos, these endodermal protrusions appeared to resemble the posttrochal region but careful examination revealed that the resemblance was superficial. Neither the posttrochal region nor any posttrochal structures formed. The apical tuft was normally located in those larvae which gastrulated completely but was often toward one side in exogastrulae. The endoderm in exogastrulae formed no enteron, whereas those which completed gastrulation appear to have one.

$A B C+1 d+2 d$-Embryos $(-2 D)$. A total of 22 embryos were prepared as whole mounts and 6 were sectioned. In more than $2 / 3$ of these embryos the pretrochal region appeared normal. The apical tuft is central and well formed, the three rows of the prototroch are symmetrical and unbroken and cephalic pits appear near the end of the second day, which is typical morphogenesis. Only two 
embryos lacked the apical tuft and these also lacked most of the posttrochal ectoderm. The posttrochal ectoderm never completely covered the endoderm (Fig. 10); the endoderm in some cases protruded as a column which was partly covered by ectoderm. A single statocyst was present in 6 embryos, and in 12 embryos a small foot appeared to be formed. No shell gland or shell ever formed. The endoderm developed diverticulae but these did not show any additional differentiation.

$A B C+1 d+2 d+3 d$-Embryos $(-3 D)$. Sixteen larvae of this type were prepared as whole mounts and 4 were sectioned. These embryos are indistinguishable from controls except for an early asymmetry which marks the site of the deleted cell. This condition has usually disappeared by the gastrula stage and is only rarely detectable afterwards. The trochophores (Fig. 11) have typical apical tufts, pretrochal regions, prototrochs and only slightly reduced posttrochal regions. Cerebral pits form, as do the typical posttrochal structures, the shell gland, the paired mantle folds and the foot with paired statocysts. The gut appears to be complete at least in some cases. The mesenchyme is so dense that no distinction could be made between control and operated embryos in this regard.

$A B C+1 d+2 d+3 d+4 d$-Embryos $(-4 D)$. A total of 5 whole mounts, and 4 sectioned embryos were prepared. The $4 \mathrm{D}$ macromere is relatively small in Dentalium and no defects of any kind can be observed an hour after the operation. There is no apparent asymmetry. All pretrochal and posttrochal organs are of normal size and shape and appear at the same time as in controls.

\section{Deletion of Micromeres}

$A B C+1 D$-Embryos ( $-1 d$ ). Sixteen embryos were prepared as whole mounts. Van Dongen and Geilenkirchen (1974) have shown by the study of cell lineage that the apical tuft is formed from derivatives of $1 \mathrm{c}$ and $1 \mathrm{~d}$. Embryos with 1d removed had apical tufts but with fewer cilia than controls. In 6 embryos from which $1 \mathrm{c}$ was deleted, the number of apical cilia was reduced. In 3 cases both $1 \mathrm{c}$ and $1 \mathrm{~d}$ were deleted from the same embryo and no apical tuft formed. All other aspects of development in these embryos appeared normal, except that there may be a reduction in the size of the cerebral pits. This cannot be adequately analysed in existing preparations.

$A B C+1 d+2 D$-Embryos $(-2 d)$. A total of 27 whole mounts and 7 sectioned embryos were prepared. These embryos show considerable morphological variability but are fairly consistent in structures formed. The apical tuft was present in all except two embryos. Cerebral pits were not observed. The prototroch had a small gap in 6 cases but was otherwise well formed. Foot tissue was found in 3 of the sectioned embryos and a statocyst in one. Areas of small celled posttrochal ectoderm present in 12 whole mounts probably represent foot epithelium. No shell gland nor shell materials were observed. Eighteen of these embryos failed to gastrulate completely, and of these 6 were exogastrulae. A stomodeum appears to be present in at least 8 embryos. 

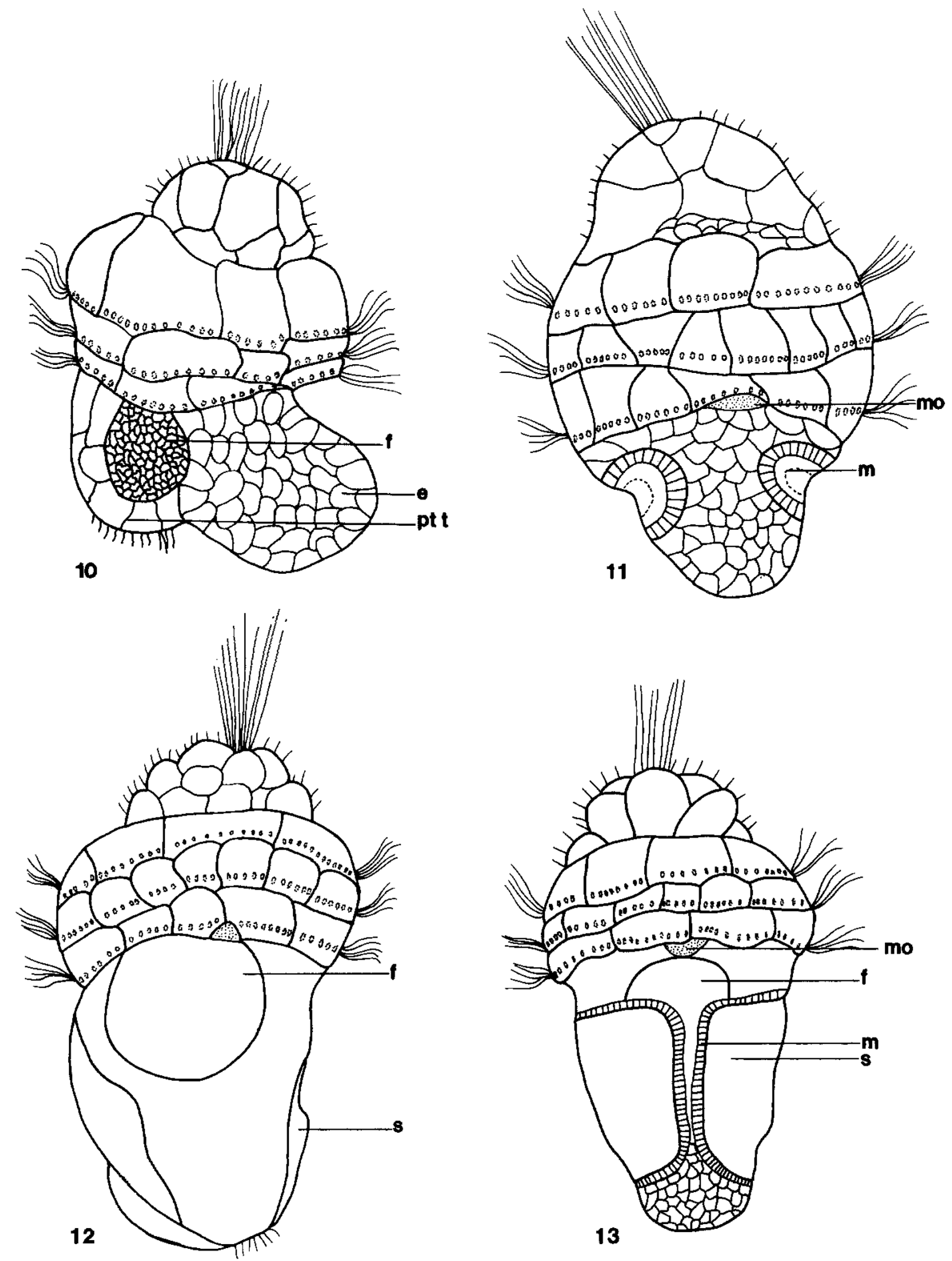

Fig. 10. Larva $24 \mathrm{~h}$ after deletion of the $2 \mathrm{D}$ macromere $(A B C+1 d+2 d$ embryo). The apical tuft is present, the prototroch is essentially normal. There is some posttrochal ectoderm and the endoderm extrudes through it. Endoderm $(e)$, Foot $(f)$, posttrochal region $(p t t), \times 230$

Fig. 11. Larva $46 \mathrm{~h}$ after deletion of the $3 D$ macromere $(A B C+1 d+2 d+3 d)$. It is essentially indistinguishable from the controls. Mantle $(m)$, mouth $(m o) . \times 230$

Fig. 12. Larva $72 \mathrm{~h}$ after deletion of the $4 \mathrm{D}$ macromere $(A B C+1 d+2 d+3 d+4 d)$. The larva is externally indistinguishable from the controls although slightly younger in appearance. Foot $(f)$, shell $(s) . \times 230$

Fig. 13. Larva $72 \mathrm{~h}$ after deletion of the $4 d$ micromere. $(A B C+1 d+2 d+3 d+4 D)$. It is indistinguishable from the controls. Foot $(f)$, mantle $(m)$, mouth $(m o)$, shell $(s) . \times 230$ 
$A B C+1 d+2 d+3 D$-Embryos $(-3 d)$. Nine whole mounts and 5 sectioned embryos of this type were prepared. The pretrochal region appeared normal in all cases with typical apical tufts and cerebral pits. The prototroch was normal. Shell appeared to be present and well formed except in two cases. The foot was present in all cases; in two cases it was greatly reduced and in the remainder somewhat reduced. Two embryos lacked statocysts, the rest had one statocyst except for one embryo which had two.

$A B C+1 d+2 d+3 d+4 D$-Embryos ( $-4 d)$. Eight such embryos were prepared, one was sectioned. These appear perfectly normal (Fig. 13). They are so packed with mesenchyme that no defects of mesoderm are apparent.

\section{Discussion}

Since Wilson's (1904) classical work on the influence of the polar lobe on the development of Dentalium, eggs with polar lobes have been studied extensively to elucidate the influence of cytoplasmic localizations on development. Wilson showed that after removal of the lobe at first cleavage both the apical tuft and the posttrochal region were absent. Removal of the lobe at second cleavage had the same effect except for the apical tuft, which was present in most $-\mathrm{pl} 2$ embryos. Wilson supposed that the factor essential for the formation of the apical tuft moved from the first lobe upward to the animal pole and became incorporated in the D-quadrant exclusively, since in isolation experiments of the micromeres at the 8-cell stage only the $1 \mathrm{~d}$ micromere formed an apical tuft. Van Dongen and Geilenkirchen (1974) demonstrated that the apical tuft is located on the cells $1 \mathrm{c}^{1111}$ and $1 \mathrm{~d}^{1111}$, which are derived from the $1 \mathrm{c}-$ and $1 \mathrm{~d}$-micromeres. In order to bring their data in accordance with Wilson's observation that after isolation of the micromeres only the 1d micromere formed an apical tuft and not the 1c micromere, they put forward the hypothesis that in normal development the cell $1 \mathrm{c}^{111}$ can only form a part of the apical tuft when it received an inductive stimulus from the D-quadrant, most probably from the cell $1 \mathrm{~d}^{1111}$. Since, however, in our experiments not only in CD-embryos the tuft is present but also in -D embryos, although reduced, the theory of Van Dongen and Geilenkirchen is untenable. Most probably Wilson's statement that only the $1 \mathrm{~d}$ micromere can form an apical tuft is incorrect. The reason may be that he based his conclusion on too few cases of isolated first quartet cells. As removal of the second polar lobe or of the D blastomere at the 4-cell stage does not result in the absence of the apical tuft, determinants for apical tuft formation are not contained in the second lobe but are divided over the $\mathrm{C}$ and $\mathrm{D}$ blastomeres at second cleavage. This does not mean, however, that the determinants for the apical tuft, localized in the first polar lobe, move upward already at the 2-cell stage so that they do not become incorporated in the second lobe. Geilenkirchen et al. (1970) found that about $60 \%$ of the first polar lobe from the vegetal side can be removed without affecting the formation of an apical tuft. As they also established that the second lobe amounts to about $65 \%$ in volume of the first lobe, one may suppose 
that determinants for apical tuft formation are localized in the apical part of the first polar lobe, which is not incorporated in the second lobe but segregated to both the $\mathrm{C}$ and $\mathrm{D}$ blastomeres at second cleavage.

The influence of the polar lobe on morphogenesis of the pretrochal region is not restricted, however, to the apical tuft. Van Dongen (1976b) showed that after removal of the polar lobe four cerebral ganglia are formed instead of the two found in the normal embryo. Although one might expect cerebral pits or ganglia to be formed in the $\mathrm{CD},-\mathrm{D}$ or $-1 \mathrm{D}$ embryos, paired cerebral pits were observed only in the $-2 \mathrm{D},-3 \mathrm{D}$ and $-4 \mathrm{D}$ embryos. This problem needs further investigation. The $-\mathrm{pl} 2$ and the $-\mathrm{D}$ embryos do not form a posttrochal region. The question therefore arises, as to how such determinants are segregated during further cleavage of this quadrant. From our data it is clear that - 1D $(A B C+1 d)$ also develops in the same way as a - p1 2 embryo. Consequently at third cleavage the lobe material is restricted to the $1 \mathrm{D}$ blastomere.

The second quartet of micromeres includes the first somatoblast.2d, a cell of great importance for morphogenesis, as it forms the shell gland and part of the foot (Van Dongen and Geilenkirchen 1974). In accordance with these data the $-2 d(A B C+1 d+2 D)$ showed a partial development of the posttrochal region, including a small foot with one statocyst, but shell gland or shell were never observed. This may be due to partial exogastrulation which occurred in most of the $-2 \mathrm{~d}$ embryos. As, however, foot tissue including statocyst was formed, an inductive influence from $2 \mathrm{D}$ or $3 \mathrm{D}$ on shell formation cannot be excluded.

The third quartet includes the $3 \mathrm{~d}$ blastomere, from which a part of the foot is derived (Van Dongen and Geilenkirchen 1974). Indeed -3d embryos show a reduction of the foot and $-3 \mathrm{D}$ embryos have a normal foot and shell. Eggs in which the macromere 4D is deleted, develop into normal larvae, which apparently do not lack any structures. Consequently in Dentalium as in Ilyanassa (Clement 1962) the 4D macromere is nutritional in nature. In molluscan embryology $4 \mathrm{~d}$ is called the mesentoblast, as descendants of this cell produce besides some entoderm the adult mesoderm. After removal of $4 \mathrm{~d}$ no defects in the larvae could be detected. This does not mean that the $4 \mathrm{~d}$ is of no importance for the development of Dentalium. As the larval mesoderm, derived from $2 \mathrm{a}^{212}$ and $2 \mathrm{c}^{122}$ is well developed in Dentalium (Van Dongen and Geilenkirchen 1974) the extensive larval mesenchyme in the $-4 d$ embryos may obscure the absence of adult mesoderm. Also there is much less regular organization of the mesenchyme in the operated embryos than in the normal embryos investigated by Van Dongen (1977).

Our data are in general agreement with the data of Clement (1962) who removed the $\mathrm{D}$ macromere at successive stages in the gastropod Ilyanassa. Also in this snail lobeless, $A B C, A B C+1 d$ and $A B C+1 d+2 d$ develop into partial larvae, which fail to form most of the adult structures. In both molluscs the shell is missing after deletion of $2 \mathrm{D}$, although the $2 \mathrm{~d}$ cell is present, which gives rise to the whole shell in Dentalium (Van Dongen and Geilenkirchen 1974) and to most of the shell in Ilyanassa (Cather 1967). Raven (1952) has put forward the theory that in Lymnaea the shell gland is induced by the 
small-celled endoderm. Later Hess $(1962,1971)$ supposed that this influence was not restricted to this small-celled endoderm but that the large-celled endoderm is capable of inductive interaction as well. Cather (1967) showed that the mesentoblast $4 \mathrm{~d}$ and even an isolated polar lobe could induce the formation of an external shell by an isolated ectoblast. As, however, removal of $2 \mathrm{~d}$ in Dentalium and of $2 c+2 d$ in Ilyanassa results in the absence of a shell, the normal competence for shell formation is restricted to special cells.

The inductive influence for shell formation is also limited to the D-quadrant and as -3D embryos both in Dentalium and Ilyanassa form an external shell, the inductive influence has been exerted prior to removal of the $3 \mathrm{D}$. Clement (1962) got some indication that a fuller differentiation of the shell was obtained, when $3 \mathrm{D}$ was removed at a late stage in the interval between the fifth and sixth cleavage, which he attributed to an inductive influence of 3D. Also in our experiments $3 \mathrm{D}$ was removed late in this interval between the fifth and sixth cleavage and this cell may have influenced the morphogenesis in the $2 d-$ cell-line, which without this support cannot form a shell. Van Dongen (1976a, b) by comparing the cell-lineage of normal and lobeless embryos of Dentalium got strong indications that the D-quadrant influences morphogenesis in the $\mathrm{A}$ - and C-quadrant. For this influence the segregation of the material of the polar lobe into the D-quadrant is essential. Within this quadrant the polar lobe material is segregated according to a fixed pattern, by which cells are specified and obtain a developmental capacity in distinct directions. For full determination of the $\mathrm{D}$-quadrant cellular interactions may nevertheless be indispensable.

Acknowledgements. We wish to thank Dr. Pierre Guerrier for his thoughtful help while we worked at Roscoff and Professor Dr. J. Bergerard, the Director of the Laboratory whose many courtesies facilitated our efforts. We also wish to note the stimulating scientific discussions with our colleague J.A.M. van den Biggelaar. C.A.M. van Dongen has been especially helpful giving unselfishly his knowledge and expertise with Dentalium for which we express our gratitude. The work of JNC was supported in part by a Faculty Research Grant from the H.H. Rackham Funds of the University of Michigan.

\section{References}

Biggelaar, J.A.M. van den: Development of dorsoventral polarity and mesentoblast determination in Patella vulgata. J. Morphol. 154, 157-186 (1977)

Cather, J.N.: Cellular interactions in the development of the shell gland of the gastropod, lyanassa. J. Exp. Zool. 166, 205-224 (1967)

Cather, J.N.: Cellular interactions in the regulation of development in annelids and molluses. Adv. Morphog. 9, 67-125 (1971)

Cather, I.N., Verdonk, N.H.: The development of Bithynia tentaculata (Prosobranchia, Gastropoda) after removal of the polar lobe. J. Embryol. Exp. Morphol. 31, 415-422 (1974)

Cather, J.N., Verdonk, N.H., Dohmen, M.R.: Role of the vegetal body in the regulation of development in Bithynia tentaculata (Prosobranchia, Gastropoda). Am. Zool. 16, 455 468 (1976)

Clement, A.C.: Development of Ilyanassa following removal of the $\mathrm{D}$ macromere at successive cleavage stages. J. Exp. Zool. 149, 193-216 (1962)

Clement, A.C.: Ilyanassa. In: Experimental Embryology of Marine and Fresh-water Invertebrates (G. Reverberi, ed.). Amsterdam: North-Holland Pub1. 1971 
Dohmen, M.R., Verdonk, N.H.: The structure of a morphogenetic cytoplasm, present in the polar lobe of Bithynia tentaculata (Gastropoda, Prosobranchia). J. Embryol. Exp. Morphol. 31, 423-433 (1974)

Dohmen, M.R., Verdonk, N.H.: The ultrastructure and role of the polar lobe in development of molluscs. In: Determinants of spatial organization (S. Subtelny and I.R. Konigsberg, eds.). New York: Academic Press (1979)

Dongen, C.A.M. van: The development of Dentalium with special reference to the significance of the polar lobe. $V$ and VI. Differentiation of the cell pattern in lobeless embryos of Dentalium vulgare (da Costa) during late larval development. Proc. K. Ned. Akad. Wet. C79, 245-266 (1976a)

Dongen, C.A.M. van: The development of Dentalium with special reference to the significance of the polar lobe. VII. Organogenesis and histogenesis in lobeless embryos of Dentalium vulgare (da Costa) as compared to normal development. Proc. K. Ned. Akad. Wet. C79, 454-465 (1976b)

Dongen, C.A.M. van: Mesoderm formation during normal development of Dentalium dentale. Proc. K. Ned. Akad. Wet. C80, 372-376 (1977)

Dongen, C.A.M. van, Geilenkirchen, W.L.M.: The development of Dentalium with special reference to the significance of the polar lobe. I, II, and III. Division chronology and development of the cell pattern in Dentalium dentale (Scaphopoda). Proc. K. Ned. Akad. Wet. Amsterdam C77, 57-100 (1974)

Dongen, C.A.M. van, Geilenkirchen, W.L.M.: The development of Dentalium with special reference to the significance of the polar lobe. IV. Division chronology and development of the cell pattern in Dentalium dentale after removal of the polar lobe at first cleavage. Proc. K. Ned. Akad. Wet., Amsterdam C78, 358-375 (1975)

Geilenkirchen, W.L.M., Verdonk, N.H., Timmermans, L.P.M. : Experimental studies on morphogenetic factors localized in the first and second polar lobe on Dentalium eggs. J. Embryol. Exp. Morphol. 23, 237-243 (1970)

Hess, O.: Entwicklungsphysiologie der Mollusken. Fortschr. Zool. 14, 130-163 (1962)

Hess, O.: Fresh water gastropoda. In: Experimental Embryology of Marine and Fresh-water Invertebrates (G. Reverberi, ed.). Amsterdam: North-Holland Publ. 1971

Kowalewsky, A.: Etude sur l'embryogenie du Dentale. Ann. Mus. d'Hist. Nat. Marseille. Zool. 1,7 (1883)

Morrill, J.B., Blair, C.A., Larsen, W.J.: Regulative development in the pulmonate gastropod Lymnaea palustris as determined by blastomere deletion experiments. J. Exp. Zool. 183, 47-56 (1973)

Raven, C.P.: Morphogenesis in Limnaea stagnalis and its disturbance by lithium. J. Exp. Zool. 121, 1-77 (1952)

Reverberi, G.: The ultrastructure of Dentalium egg at the trefoil stage. Acta Embryol. Exp. 12, $31-43(1970)$

Reverberi, G.: Dentalium. In: Experimental Embryology of Marine and Fresh-water Invertebrates (G. Reverberi, ed.). Amsterdam: North-Holland Publ. 1971

Reverberi, G. : The fine structure of the ovaric egg of Dentalium. Acta Embryol. Exp. 14, $135-166$ (1972)

Timmermans, L.P.M., Geilenkirchen, W.L.M., Verdonk, N.H.: Local accumulation of Feulgenpositive granules in the egg cortex of Dentalium dentale L. J. Embryol. Exp. Morphol. 23, 245-252 (1970)

Verdonk, N.H.: The effect of removing the polar lobe in centrifuged eggs of Dentalium. J. Embryol. Exp. Morphol. 19, 33-42 (1968a)

Verdonk, N.H.: The relation of the two blastomeres to the polar lobe in Dentalium. J. Embryol. Exp. Morphol. 20, 101-105 (1968b)

Verdonk, N.H., Geilenkirchen, W.L.M., Timmermans, L.P.M.: The localization of morphogenetic factors in uncleaved eggs of Dentalium. J. Embryol. Exp. Morphol. 25, 57-63 (1971)

Verdonk, N.H., Cather, J.N.: The development of isolated blastomeres in Bithynia tentaculata (Prosobranchia, Gastropoda). J. Exp. Zool. 186, 47-62 (1973)

Wilson, E.B.: Experimental studies on germinal localization. I. The germ regions in the egg of Dentalium. J. Exp. Zool. 1, 1-72 (1904)

Received October 12, 1979; Accepted November 21, 1979 